Speculative

Social

World

Understanding by Politics

World

by Speculative

by Social

Politics

Speculative

Human

Social

by Understanding

by Understanding

Human

Speculative

World

by

by World

by Speculative Design

Speculative

by Human

World

Social
by
by Speculative

Politics

Social

Social

World
? Undesign

Critical Design

Social

Understanding

? Human

World

Understanding

Human

Speculative Social

Social

? Design Culture

?

Social

Building

Critical

? Design Culture

Human

Biased Design

Speculative

World

Human

Critical

Human

Critical

Social

Speculative

Social
Speculative

Critical

Human

by

World

? Speculative Social by

by

Critical Practice

Social

by

by

Design Culture

Social

Social

Social

by

by

by

by

by

by

by Biased Design 
Understanding

Human

by

Social

Speculative

by

Building

Aesthetic Dimension

Social

Social

by

by

Social

Undesign

Social

Politics

by

Speculative

by

by

by

Social

by

by

Critical

Speculative Social

Speculative

Design Culture

Undesign

Politics

?

?
Design Culture

Speculative Design

Design Culture by

Care

by Design Culture

by

Critical

by

Design Culture

Human

Design Culture
World

Social

World$$
?
$$

Design Culture

World

World

Social

Design Culture

Critical

by Understanding

by Critical

Critical Design

Social

Human

Design Culture

Social

Social ? Speculative Design

by

by
Social
Design Culture

Social

World

World

Social

Critical

Social

by Social

Social

Social
Social
by Design Culture
Design Culture
by Human

by Speculative Design ?

by World

Undesign 


\section{The ineliminable}

\section{aesthetic dimension}

of apt

Janneke W/esseling 
The notion of critique in art has a long history. It is inextricably bound up with art production from the early days of Modernism onwards, in the sense of art as critical self-reflection as well as in the sense of art as socially/politically engaged critique. Marcel Duchamp comes to mind, of course, as well as the Dada movement and the Russian Constructivists who played a leading role in the Russian Revolution. The Stijl experiments in art, architecture and design were driven by a reduction to essentials, not only in formal terms (lines and planes, and black, white and primary colors), but also as a model for a just and harmonious human society.

From the 1930s onward, the development of a coherent critical aesthetic theory in Europe was largely inspired by a more philosophical notion of «critique» as propagated by the Frankfurt School, with Theodor Adorno and Max Horkheimer as its leading proponents. Adorno's approach to aesthetics and his critical social theory are indebted to Karl Marx. His writings on aesthetics center around the concepts of authenticity and of the autonomy of the art object. In Adorno's thinking, such notions are preconditions for the role of art as an antithesis to society, in a dialectical struggle against the culture industry and the resulting commodification of art. Adorno's thinking resonates in art theory up until the present day.

In America, on the other hand, art critic and advocate of Abstract Expressionism Clement Greenberg defined the art of the avant-garde largely in terms of (self-)critique and self-reflection.' Under his influence, developments in American Modernism took a formalist and aesthetic turn. Notions of «autonomy» and «reductionism» played a key role here as well, but in a narrower sense than was the case with Adorno. In America, during the 1940s and 1950s abstraction in art was propagated as a utopian and timeless, universal visual language. Politically speaking, this abstract and universal language acted as a counterweight to Social Realism in communist countries, in the name of the Western belief in the freedom of the individual - propagated by the CIA, which secretly supported Modernist art (Staal 2019).

In subsequent decades, ideas on the critical function of art gradually shifted away from Modernist notions of autonomy and reductionism towards explicit socially and politically engaged critique. This happened with conceptual art, Fluxus, appropriation art, institutional critique, relational aesthetics, «postproduction», etc. It can be safely stated that up until the present day, contemporary art is regarded as critical or "subversive» by its very nature. For contemporary artists, curators and theorists, the critical or subversive nature of 
2 Although «research in and through art» may be the most adequate term, I use «artistic research,» as this is the term most commonly used in Europe.

3 An important institutional factor in the coming into existence of artistic research are the «Bologna Agreements,» 1999. The Bologna Agreements, however, do not explain or do justice to the relevance of the notion of research in art since conceptual art at the beginning of the 1960s. art practice and of the art object is selfevident and a conditio sine qua non for any art practice.

Since the turn of the millennium - Documenta $X$, organized by Catherine David in 1997, may serve as a landmark - art production as (self-)critical subversion has reached the point of virtually obliterating the artwork as object or event, as well as its authorship. The British philosopher Peter Osborne addressed the «postconceptual condition» of art in his Anywhere or Not at All: Philosophy of Contemporary Art (2013). Post-conceptualism, according to Osborne, prioritizes discursive content and the process of art production over a contingent artistic outcome of the production process. The «post» of post-conceptionalism refers to the idea of conceptuality as the necessary condition of contemporary art. Osborne traces this post-conceptual condition back to conceptual art of the 1960s and 1970s. Osborne argues that in the constant questioning of the role of art and artist, and in the increasing attempts to bridge the distance, or even the difference, between art production and critical reflection, it is has become impossible to distinguish the roles of artist, curator and institution (museum, Kunsthalle, artist-run exhibition spaces, biennial, Documenta) in the production of art.

This raises a fundamental question of the status of the art object: where is it situated and how can it be perceived or experienced? Osborne concedes that art has an «ineliminable - but radically insufficient - aesthetic dimension: all art requires some form of materialization, that is to say, aesthetic - felt, spatio-temporal - presentation» (Osborne 2013: 48). I take this to mean that however conceptual or ephemeral the artwork may be, it remains pertinent for it to be experienceable through its visual, embodied or otherwise sensual form.

Closely related to the «postconceptual condition» of art, a new field of research emerged, called artistic research (alternatively "practice-based research in art» or "research in and through art»). ${ }^{2}$ In my view, artistic research, even when it is not limited to visual art but includes all artistic disciplines, is intimately linked to the history of art-as-critique and to the conceptuality of art as briefly sketched above. ${ }^{3}$

Theoretical reflection plays a central role in conceptual art in America from the late 1960s on. In conceptual art, art could not be separated from history and politics. It was regarded as crucial for the artist to engage with the world in a political and theoretical way. As a consequence, language acquired an important role in art 
practice. Text could be part of the artwork or even be the artwork. Not only did artists reflect on societal and political issues - think of artists such as Hans Haacke and Dan Graham - but also on art practice itself, in a critical and self-reflexive way. Doing art is questioning how to do it, as John Baldessari once said, meaning that critical reflection on one's artistic procedures or doings is essential to the artistic process or is the work itself.

Another important factor in the emergence of theory and criticism as artistic practice were feminist art practices that aimed to reveal power structures and patterns of hierarchy in society. Feminist art practices focused on the body and on the dichotomies of matter and meaning, thinking and doing, theory and practice - dichotomies that are deeply entrenched in Western culture.

To conclude, at the present day, following the long tradition of Modernist art, contemporary art production and critique are nearly exchangeable, with the caveat of the aesthetic dimension of the art object and its sensual, perceptual, experiential nature. Critique in visual art is necessarily tied up with conceptuality, meaning that art practices by definition question the premises of the status of the artwork itself, such as copyright, authorship, distribution, etc.

In the following I will look into the question of the aesthetic dimension of present-day art in the light of its critical potential. I will address the matter of art as «discursive practice» and I will show how the age-old dichotomy of theory and practice is contested in contemporary thinking as well as in contemporary art. I will offer a hypothesis on how art practices and the critique they enact or embody may be understood. Three different cases of artistic production, by Gustav Metzger, Alfredo Jaar and Jessica Stockholder, serve as points of reference. My argument draws on concepts that are developed in the thinking of so-called New Materialist philosophers and the «agential realism» of Karen Barad.

\section{Case \#1}

Gustav Metzger: Ethics into Aesthetios

During his life-long career, Metzger (Nuremberg, 1926-London, 2017) propagated Auto-Destructive Art (ADA). For each ADA work or event, Metzger created particular conditions for its self-destruction. The destruction process could be caused by acid, glue, fire-arms, burning, compression, corrosion, electrolysis, natural forces such as wind or light, sun energy - the list of materials and techniques included in Metzger's second «manifesto auto-destructive art» (published on March 10, 1968) is long. Sometimes the destruction would follow immediately after the artwork was made, in a single blast; the destruction 
process could also happen slowly, over a period of many years. According to ADA principles, the maximum life span of the artwork is 20 years.

ADA was aimed, first of all, against capitalism. Self-destructive art pointed forward to the suicide of humans and machines that according to Metzger is certain to happen. The suicide will be the consequence of Western capitalism, with its widening gap between the rich and the poor and with the increasing effects of technology on daily life. ADA not only confronted the capitalist system, but also the art world itself, which Metzger regarded as

a very tight little world. It has capital investments such as dealers' galleries, dealers' stocks, artists' studios and their stock of work. ... Unless he can pass through the dealers' one-man show hoop, unless he is able or prepared to become part of a dealer's «stable», the living artist in England does not exist as far as the official art world is concerned. (Metzger / Copeland 2019: 111)

Self-destructive or not, Metzger left us an important body of work that seems, in these times of humanitarian and ecological crisis, more pertinent than ever. Some examples: «In Memoriam» (2015) is a memorial to the victims of the Holocaust in the shape of a labyrinthian sculptural installation constructed of man-size cardboard boxes.

Metzger's «Mass Media: Today and Yesterday» (1972/2017) is made with huge piles of newspapers. The public is invited to cut out articles and paste them on the wall. One of Metzger's earliest auto-destructive works is the performance «Acid Nylon Painting» (1960/2017). Metzger stretched nylon fabric onto a wooden frame and treated it with acid, until it was covered with holes and finally disintegrated.

In 1939, Metzger, child of Polish-Jewish parents, was brought to London by the Refugee's Children's Movement, together with his brother Mendel. Their parents and all other family members were killed by the Nazis. Metzger's activist art practice can be understood in this historical context, and parallels have been pointed out between his art and the thinking of Theodor Adorno. But while Adorno asked whether poetry could still be written after Auschwitz (and originally answered this question in the negative), it was Metzger's conviction that after Auschwitz, making art was more urgent than ever. «Auto Destructive Art demonstrates man's power to accelerate disintegrative processes of nature, $)$ Metzger wrote in 1960 in an early manifesto. In our postcapitalist era, few people will doubt the acceleration of the disintegration of nature by human action. At the end of the 1990s, Metzger concluded that the worldwide catastrophe against which he had tried to mobilize people for decades, was unavoidable and was happening at full speed. An «aesthetics of disgust» was his answer 
to a society gone insane. Doing art for him was a reflection on the question of how we can live well, together with all other living creatures. «People always think that an artist who destroys, destroys art. I am telling you: this art gives people the beauty that fits our time») (Metzger 2018).

\section{Rehabilitation of practice}

In the sciences, «practice» has long been, and often still is, regarded as subordinate and subservient to theory. Many scholars look down on practice as being merely the handwork in the laboratory that is needed to support or offer proof of theory. The truly important work is theoretical - that is, the work of the mind. The struggle of art academies in Europe to gain recognition for artistic research by universities can largely be explained by this hegemony of theory.

From a historical point of view, the hierarchy of theory over practice originated in the age-old tradition in Western culture of valuing vita contemplativa over vita activa. The predominance of mind over body may be traced back to Plato and to Saint Augustine's embrace of Platonic thinking, as argued by Hannah Arendt in The Life of the Mind (1978). Like Plato, Aristotle held deductive thinking in high esteem and downplayed experiment.

According to the American philosopher lan Hacking ([1983] 2010), the disbalance of theory and experiment was reversed with the scientific revolution of the 17th century, in particular with the thinking of Francis Bacon (1561-1626). During the scientific revolution, practical experiment «was officially declared to be the royal road to knowledge, and the schoolmen were scorned because they argued from books instead of observing the world around them» (Hacking [1983] 2010: 149). But times have changed, Hacking tells us, and today the history of the sciences is almost always written as a history of theory rather than of experiment: philosophers of science «constantly discuss theories and representations of reality, but say almost nothing about experiment, technology, or the use of knowledge to alter the world.» Hacking notes that the theory/experiment status difference is umodelled on social rank.» His Representing and Intervening contests the theory-dominated history of science. It is Hacking's conviction that «a question posed in terms of theory and experiment is misleading because it treats theory as one rather uniform kind of thing and experiment as another» (Hacking [1983] 2010: 162).

Earlier in the 20th century, the Spanish philosopher and social theorist José Ortega y Gasset addressed the state of affairs in a series of lectures at the University of Santander, published as Méditation sur la Technique (1935). Without technique, Ortega y Gasset 
4 The New Materialist strain of thinking goes by a number of different names, among them New Materialism, Object Oriented Ontology, and Speculative Realism. argues, man could not exist and would never have existed. Yet it is the policy, even the foundation, of the University (written by him with capital $U$ ) to ignore technique by completely excluding it from its own sphere and by delegating it to specialized schools. Therefore scholars educated by the University find themselves «paralyzed in the face of the most pressing problems of their time,» while on their side the engineers, lacking the usynthetic and panoramic education that only the University has to offer, $\gg$ are incapable of dealing with problems that technique poses for mankind (Ortega y Gasset [1935] 2017: 10). According to Ortega y Gasset, human life is «fundamentally» production and fabrication. Production therefore is primary, and thought, theory and science follow from it

For Hacking, practice is characterized by experiment and by the intervention in reality (instead of the representation of reality). Hacking calls himself an «ontological realist," who believes the entities, states and processes described by correct theories are real and not mere «constructs of the human mind for organizing our experiments» (Hacking [1983] 2010: 2). In certain respects, Hacking's Representing and Intervening anticipates New Materialism. ${ }^{4}$ Under the heading of New Materialism, a diverse group of thinkers is brought together who agree in one fundamental respect: the existence of a reality, or a world, of objects out there, independent of our gaze and of our knowledge of them, independent also of our access to these objects. These thinkers aim «to preserve the autonomy and irreducibility of substance» (Bryant 2011: 26). New Materialism embodies the attempt to leave Kant and Hume behind and to sidestep the subject-object divide. Contempt for practice signifies the subject-object distinction, or the Cartesian habit of mind that the New Materialists aim to overcome.

A leading proponent of this strain of thinking is the American philosopher and physicist Karen Barad, even though she prefers to call herself an «agential realist.» It is Barad's ambition «to contribute to the founding of a new ontology, epistemology and ethics, including a new understanding of the nature of scientific practices.) She labels her philosophical approach «agential realism,» "as an epistemologicalontological-ethical framework that provides an understanding of the roles of human and nonhuman, material and discursive, and natural and cultural factors in scientific and other social-material practices,,$>$ in an attempt «to rethink fundamental concepts that support binary thinking including the notions of matter, discourse, causality, agency, power, identity, embodiment, objectivity, space, and time» (Barad 2007: 25-26) 
Barad emphasizes that «agential realism does not merely offer a unified theory of cultural and natural forces, but inquires into the very practices through which they are differentiated» (Barad 2007: 66). Agential realism wants to provide an understanding of «materialization,» recognizing «matter's dynamism.» It is not the scope of this text to offer an interpretation of Barad's rich and complex thinking. I want to focus here on the central role of matter and materialization, and of practice, in her philosophy. Barad does not refer to matter as a fixed substance, but rather as a process of «iterative intra-activity.» «Matter," in her view, "refers to phenomena in their ongoing materialization» (Barad 2007: 151).

Barad shares Hacking's critique of representationalism and his «nonrepresentationalist realist account» of scientific practices. She elaborates his critique by proposing that both experimenting and theorizing are «dynamic practices that play a constitutive role in the production of objects and subjects, and matter and meaning» (Barad 2007: 56). Theorizing and experimentation, according to Barad, are not about intervening, because «intervening» implies an intervention into a given situation or into reality from the outside. Theorizing and experimentation are rather about what she calls «intra-acting from within» - that is, as part of the phenomena produced, in a reciprocal entanglement.

Barad brings theory and experiment closer together and, rather than reversing hierarchies between theory and practice, aims to break down the barriers between the two. She is undoing the "fracture» between them, as Bruno Latour calls it: "The difference between theory and practice is no more a given than the difference between content and context, nature and society. It is a divide that has been made. More exactly, it is a unity that has been fractured by the blow of a powerful hammery (Latour 1999: 267).

It may not be too much to speak of a rehabilitation of «practice.» Tellingly, chapter 4 of Barad's Meeting the Universe Halfway is entitled «Agential Realism: How Material-Discursive Practices Matter.» In my view, artistic practices are «material-discursive practices» par excellence. To refer again to Osborne as quoted above: all art requires some form of materialization, that is to say, aesthetic - felt, spatiotemporal - presentation. Artworks, as material-discursive phenomena, simultaneously «perform» on two levels: they refer to a world out there, carrying a message or enunciating something about that world; and they speak about themselves in their particular materialized way of being and in relation to art discourse. Following Barad, one could say that art works derive their meaning or create meaning from this entanglement, from this particular interaction between world and material form. In art practice, doing and knowing, thinking and making, the material and the discursive, representing and intervening, are 
not two separate or different things. They happen in and through each other, in a continuous process of becoming. As Barad asserts in an interview: «Knowing is a direct material engagement, a cutting together-apart, where cuts do violence but also open and rework the agential conditions of possibility. There is not this knowing from a distance») (Interview with Karen Barad in Dolphijn/van der Tuin 2012: 52).

According to Osborne, the aesthetic dimension of art is ineliminable but radically insufficient. He argues convincingly that under the post-conceptual condition, discursive content and production process of the artwork are prioritized over any artistic outcome or "product.» From this follows that the aesthetic dimension is necessarily insufficient. That is to say that the question of the aesthetic - felt, spatio-temporal dimension of the artwork, as a precondition for its discursivity, remains unresolved. New Materialist thinking and its emphasis on the entanglement of matter and discourse may be of help here.

Case \#2

A1fredo Jaar: Shadows

This artwork hurts, physically as well as emotionally. A life-size digital projection of a black and white photograph in a darkened room shows two women who raise their arms in lament, crying out loud. In the background a hilly landscape gradually darkens and disappears. Then the silhouettes of the two women become brighter and brighter, until they blind the viewer. Suddenly the projection screen turns black. The image of the two women is now burnt onto the retina of the viewer. The after-image appears, two shadows on the black screen, or, upon closing the eyes, in red behind the eyelids. The eyes are still in shock when the photograph is projected once more and the cycle restarts. The original photograph, used by Alfredo Jaar in his film installation «Shadows» (2018), was taken by photojournalist Koen Wessing (19422011) in Nicaragua in 1978, when the dictatorial regime of President Somoza was challenged by the Sandinista National Liberation Front. In the bombarded city of Estelí, Wessing came across a group of people carrying the dead body of a farmer towards a pick-up truck. Wessing followed the truck, and upon arrival at the farm his camera caught the two daughters of the farmer at the moment of receiving the bad news.

The blinding light in Jaar's installation has a twofold meaning: as a metaphor of enlightenment, in the sense of insight and truth, and as a metaphor of loss, the loss of images. It is this loss that Jaar attempts to prevent. The viewer cannot get rid of the image that is aggressively burnt onto the retina, and therefore, for a short while at least, becomes a witness. Simultaneously, Jaar questions the possibility of photo- 
graphic representation, because of the unbridgeable gap between the experience of those who witnessed the event and what can be represented by the photograph. According to Jaar, the truth about a tragedy can be understood better through words and through the emotions of victims than through pictures. In our so-called visual culture, photographs and testimonies are lost in a sea of images, according to Jaar. Nonetheless, Jaar sticks to imagery. The exhibition in Rotterdam where «Shadows» was shown was not accompanied by text.

In 1973, at the age of 17, Jaar witnessed the violent take-over by General Pinochet in Chile. As a film maker and visual artist, he developed an "aesthetics of resistance.» Through exhibitions, films, interventions in public space, debates and art-theoretical writings, Jaar draws attention to the violation of human rights, genocide, refugees and border conflicts, trying to represent the non-representable.

"Shadow/s» is dedicated to two series of photographs by Wessing, the one on Chile in 1973, the other on Nicaragua in 1978. Shortly after his return from Chile, Wessing published the photo book Chili, a book without text. In a horizontal show/case, curled up contact sheets are presented. Digitalized reproductions of photos are hanging on the walls, complete with the numbering of the photos on the roll of film. In doing this, Jaar wants to clarify Wessing's working method. Each time Wessing left home for a trip, say of ten days, he would bring ten rolls of film with him: 36 shots a day. That would do. Wessing would patiently wait for the right moment, and take the picture. A picture does not come into being in a second, Wessing once said in an interview: «you can simply wait for people to fall into the frame in the right manner. You can see it coming when an old man and a playing child will pass each other in the street» (Terreehorst 1993: 12).

Jaar put the exhibition together with utmost care. The photographs are hanging with a distance of 26 centimeters between them, to enable concentrated attention for each individual image. That precise set-up makes the photographs rise up from the specific historic events and become a universal charge against human injustice. A woman holding up a portrait photograph of her missing husband for the camera: this is something that is happening every day in every part of the world.

Despite Jaar's doubts about the power of images in our time, he created an exhibition that has enormous power of expression. He refers to the Italian politician and writer Antonio Gramsci: «Against the pessimism of the intellect, Gramsci proposed the optimism of the will. This is where I find myself today, not completely convinced» (Jaar / Valdés 1999). Jaar demonstrates how doubt and ambivalence can be a condition for deep social and political engagement. Against his better 
judgment, Jaar developed an art practice that is rooted in the material presence of images and our sensual experience of them (Jaar 2019).

Art practice and deictic practice

For a deeper understanding of the material-discursive character of artworks and how they perform meaning, I propose to take a look at the concept of deixis. German-born American philosopher and phenomenologist Albert Borgmann discusses this concept in his Technology and the Character of Contemporary Life (1984). In this book, Borgmann offers an analysis of the problems we encounter in a society that is dominated by technology. Written some 30 years ago, his analysis of «the character of technology» and of its role in contemporary life, is compelling and highly topical, and at times even prophetic of our present time and the digital age we are living in.

Like Hacking and Ortega y Gasset, Borgmann addresses the problem of how philosophical analysis has traditionally ignored human making, and that one will look in vain for philosophical reflections on technology. Borgmann argues that early scientific theories had both world-articulating and world-explaining significance, contrary to the case of modern science. With the progress of science, which is «marked by improvements in the scope, precision, and consistency of the laws») (Borgmann 1984: 25), the connection of world articulation and world explanation was undone (since then, New Materialist thinking is making an effort to «re-do» this connection). Borgmann distinguishes «articulation» and «explanation» as follows. In gaining greater explanatory power in the deductive-nomological (or subsumptive) sense, scientific laws lost their power of world articulation. Borgmann defines «articulating» as «to outline and highlight the crucial features of something.» Articulation satisfies the request for "an explication of a concrete thing or event» - rather than aiming to discover universal laws (Borgmann 1984: 25). He refers to this type of articulation as deictic explanation. Different from scientific explanation and its search for laws, deictic explanation raises questions of value and meaning. It does this by pointing out the significance of a particular thing in its concreteness. In Borgmann's view, art has always been «the supreme deictic discipline.»W While Aristotle's theories were explanatory in both senses, during the course of history scientific theories became ever more powerful and traditional deictic explanations lost their force.

The word «deictic» comes from Greek deiknynai, which means to show, to point out, to bring to light, to set before one. Borgmann's description of deictic discourse seems particularly relevant for art practice:

Speakers of deictic discourse never finally warrant the validity of what they tell but point away from themselves to what finally 
matters; they speak essentially as witnesses. Enthusiasm gives deictic discourse the force of testimony. Sympathy requires that one testify not simply by setting out in some way what matters, but by inviting the listener to search her experiences and aspiration; and so one ensures that the listener is as fully engaged as possible by the concern to be conveyed. Sympathy gives deictic discourse the force of appeal. (Borgmann 1984: 178)

As said, a deictic explanation articulates a thing or event in its uniqueness (Borgmann 1984: 72). Deictic explanation is opposed to both apodeictic (based on scientific laws) and paradeictic (or paradigmatic - the delineation of a pattern that can be examined as regards its consistency and precision) explanation. Deictic explanation raises the value question and helps to orient ourselves: what is worthy of our attention, our efforts, in relation to our practices? What problem is worthy and in need of explanation or transformation? In other words, deictic discourse is about something that addresses us in its own right and constitutes a center, a focal point, by which we can orient ourselves.

Indeed, art practice, as deictic practice, «articulates a thing in its uniqueness.» Artworks "point out something in its significance,» by enacting this particular something in a unique way, and such that it can be experienced by a spectator. This happens in its specific material-discursive form: the material and discursive cannot be separated, they happen in and through each other. Artworks create meaning and raise the value question: what is worthy of our attention, our engagement? To articulate, Borgmann reminds us, means both to establish a unique thing or event, as well as to disclose or reenact it. Art practices therefore act as deictic discourse:

Deictic discourse ... illuminates what concerns me and, if successful, provides you with an understanding that will move you to act as I have been moved. It moves us to act. Deictic explanation discloses something to us and elicits active assent. It does not have the power of proof, nor does it have to do with notions of truth. A deictic explanation remains contestable because it cannot, nor does it want to, control its subject matter or the conditions of its reception. (Borgmann 1984 : 181)

\section{Case \#3}

Jessica Stockholder

A recent series of artworks by Jessica Stockholder, entitled «Assist,» consists of sculptures that literally cannot stand on their own and need the support of other sculptures or objects. At her exhibition «Stuff 
Mattersı at the Centraal Museum in Utrecht (2019), a 16th-century stone sculpture of a saint is tied to a colorful, abstract, metal object by Stockholder, firmly lashed up by a bright yellow bungee cord. One object is grafted onto another.

Stockholder (born Seattle, 1959) started her artistic career as a painter. But from the beginning she was dissatisfied with the limits of the frame and of the two-dimensional surface. In transgressing these boundaries by literally connecting objects, her work evokes a transition zone where edges of objects meet and where they connect to their surroundings. For Stockholder, these «encounters» are metaphors for issues of autonomy and individuality, not only in regard to the art object or artisthood, but in regard to varying domains in life.

Stockholder was invited by the Centraal Museum to exhibit her work and simultaneously interact with the collection of the museum. She «interlaced» about 60 varying art objects with her own work, using the method of "assemblage» that is characteristic of her practice.

The museum is no white cube to Stockholder. Everything she finds there can be used in her installations, everything can be given a voice: windows, walls, artworks, stairs. She connects these elements by way of color. In Utrecht, walls had been painted with broad, rough brush-marks. Scaffolding is part of a comprehensive sculpture, enabling a view from above. The installation «Extra Mural Coupling» connects interior and exterior of the building, by way of mirrors, windows and long ropes.

No matter how sculptural and three-dimensional Stockholder's work may be, its character is primarily pictorial, conceived from color and surface. "Lay of the Land,》 made of orange-colored shop baskets, wooden bar stools, hanging lamps, painted mirrors and a Persian tapestry, is very much a three-dimensional painting. The main actors in «Fish out of Water» are wooden bookcases by Gerrit Rietveld. Stockholder selected them because of their thick layers of damaged and worn paint - which may be precisely the reason they have never been exhibited before. She is fascinated by the skin of paint, the border where the object and its surroundings interact. Rietveld's shallow bookcases are made to stand upright upon platforms designed by Stockholder, again with the aid of bungee cord.

Stockholder attempts to connect the experience of timelessness and stability of the framed painting with the opposite experience of movement and ephemerality. In the first instance, this may make her work seem confusing and chaotic. After that, it is a pure sensual celebration of beauty and freedom. 
A deictic practice derives its critical force from pointing to a thing in its concreteness. In doing so, it raises questions of value and meaning. A deictic practice is a critical and explanatory practice in that it selects and articulates a concrete event or thing by foregrounding and highlighting it. As stated above, artworks, as material-discursive phenomena, simultaneously «perform» on two levels: they refer to an outside world, carrying a message or enunciating something about that world; while at the same time they speak about themselves in relation to art discourse in their particular materialized way of being. Each artwork refers to a reality out there - through a narrative, a political message, etc. - and positions itself as artwork in an art context and among a particular body of art-works.

The three art practices discussed above differ from each other in many respects. However, all three of them demonstrate the deictic and critical character of contemporary art. Gustav Metzger's work is driven by a great sense of urgency; his self-destructive art is a powerful tool to evoke and confront his public with the (self-)destructive drive of humans. Alfredo Jaar's work embodies the force of witnessing at its fullest, by investing images with the power of testimony. The work of Jessica Stockholder speaks of the nature of objects as concrete things, and presents things and objects as entangled and interdependent. Thereby it addresses ideas on autonomy and individual identity.

These practices embody a particular way of perceiving the world and our interaction with it, and each of them is the embodiment of a clearly articulated aesthetics. They are a call to action on the part of the viewer, in performing a radical openness in order to find new perspectives on how we can deal with the world we live in or to imagine it differently. These new perspectives are arrived at in a continuous interaction between thinking and doing, an interaction that is focused on sensual and embodied experience. "Stuff matters," as Stockholder puts it.

Artworks enact realities in a concrete and unique way. Art gains explanatory power through the sustained care and utmost precision in the way it is made and presented. Artworks show, point out, bring to light, set before us a problem that is worthy of our attention. The aim is to testify not simply by setting out in some way what matters, but by inviting the viewer to search their experiences and aspirations. 
Barad, Karen (2007): Meeting the Universe Halfway.

Quantum Physics and the Entanglement of Matter and

Meaning, Durham, NC/London: Duke University Press.

Borgmann, Albert (1984): Technology and the Character of Contemporary Life: A Philosophical Inquiry, Chicago: University of Chicago Press.

Bryant, Levi (2011): The Democracy of Objects, Ann Arbor, MI: Open Humanities Press.

Dolphijn, Rick/van der Tuin, Iris (2012): New Materialism: Interviews \& Cartographies, Ann Arbor, MI: Open Humanities Press.

Greenberg, Clement (1939): «Avant-Garde and Kitsch.» Partisan Review, 6/5, pp. 34-49.

Hacking, Ian ([1983] 2010): Representing and Intervening: Introductory Topics in the Philosophy of Science, Cambridge: Cambridge University Press.

Jaar, Alfredo (2019): Shadows: Exhibition in the Nederlands Fotomuseum, Rotterdam, January 19-May 5, 2019.

Jaar, Alfredo/Valdés, Adriana (1999): Alfredo Jaar: Studies on Happiness 1979-1981, Barcelona: Actar.

Latour, Bruno (1999): Pandora's Hope: Essays on the Reality of Science Studies, Cambridge, MA: Harvard University Press.

Metzger, Gustav (2018): «Ethics into Aesthetics.» Exhibition at West, contemporary art gallery, The Hague, Netherlands, 2018.
Metzger, Gustav/Copeland, Mathieu (2019): Gustav Metzger: Writings (1953-2016), Zurich: JRP|Editions.

Ortega y Gasset, José ([1935] 2017): Méditation sur la Technique, trans. David Uzal, Paris: Éditions Allia.

Osborne, Peter (2013): Anywhere or Not At All: Philosophy of Contemporary Art, London: Verso.

Staal, Jonas (2019): Propaganda Art in the 21st Century, Cambridge MA: MIT Press.

Terreehorst, Pauline (1993): «Koen Wessing, the Narrative Photographer.» In: Tineke De Ruiter/Pauline Terreehorst, Koen Wessing, Amsterdam: Fragment Uitgeverij, pp. 8-41. 
References

211 